\title{
Sodium cromoglycate and ipratropium bromide in exercise-induced asthma
}

\author{
N C THOMSON, K R PATEL, AND J W KERR \\ From the Department of Respiratory Medicine, Western Infirmary, Glasgow, UK
}

\begin{abstract}
Thomson, N C, Patel, K R, and Kerr, J W (1978). Thorax, 33, 694-699. Sodium cromoglycate and ipratropium bromide in exercise-induced asthma. In thirteen patients with extrinsic asthma the effects of placebo, sodium cromoglycate, ipratropium bromide, and ipratropium bromide plus sodium cromoglycate were studied in a random double-blind fashion to assess their inhibitory action in exercise-induced asthma (EIA). Exercise testing consisted of steady state running on an inclined treadmill for up to eight minutes. In eight of the 13 patients studied the baseline ratio of expiratory flow at $50 \%$ vital capacity (VC) breathing helium-oxygen $\left(\dot{\mathrm{V}}_{50} \mathrm{He}\right)$ to $\dot{\mathrm{V}}_{50 \text { air }}$ was over 1.20 and they were called responders; the remaining five patients were called non-responders. There was a significantly lower baseline maximum mid-expiratory flow rate (MMEF) in nonresponders $(\mathrm{P}<0.02)$ as compared to responders but no difference in forced expiratory volume in one second $\left(\mathrm{FEV}_{1}\right)$ or forced vital capacity $(\mathrm{FVC})$.

Sodium cromoglycate $(\mathrm{P}<0.02)$, ipratropium bromide $(\mathrm{P}<0.01)$, and ipratropium bromide plus sodium cromoglycate $(\mathrm{P}<0.01)$ all significantly inhibited the percentage fall in $\mathrm{FEV}_{1}$ after exercise in the responders. Ipratropium bromide had no preventive action in non-responders, unlike sodium cromoglycate $(\mathrm{P}<0.05)$ and ipratropium bromide plus sodium cromoglycate $(\mathrm{P}<0.02)$.

It is postulated that mediator release is an important factor in development of EIA in most extrinsic asthmatics, whereas cholinergic mechanisms are relevant only in those patients in whom the main site of airflow obstruction is in the large central airways.
\end{abstract}

Although the mechanisms involved in exerciseinduced asthma (EIA) are unknown, both the release of bronchoconstrictor mediators (Lancet, 1976) and reflex bronchoconstriction secondary to stimulation of vagal receptors (Gold, 1975) have been postulated. Sodium cromoglycate (SCG), which inhibits the release of mediators from mast cells (Orr et al, 1970), may have a preventive effect in EIA through a similar mechanism (Davies, 1968). The inhibitory action of anticholinergic agents is more variable (Godfrey and König, 1976; Tinkelman et al, 1976), although any lack of effect does not appear to be due to inadequate cholinergic blockade (personal observations) as had been previously suggested (Tinkelman et al, 1976). In an uncontrolled study reported by McFadden et al (1977) the combination of SCG and the anticholinergic drug ipratropium bromide (IB) inhibited EIA in all patients studied, whereas IB alone inhibited only those patients with mainly large airways obstruction as assessed by changes in density dependence of maximal expiratory flow rates. SCG was not given alone. They concluded that the airway response to exercise in asthmatics is heterogenous in terms of predominant site of flow limitation and with regard to mechanism.

The purpose of this study was to investigate in a double-blind manner the effects of SCG, IB, and IB plus SCG in the prevention of EIA in patients whose main site of airflow obstruction was in small and large airways as assessed by maximal expiratory flow rate response to low density gas breathing. It was hoped that these results might further define the role of mediator release and vagal action in EIA.

\section{Methods}

Seven men and six women (age 17-33 years) with extrinsic bronchial asthma and reversible airflow obstruction gave informed consent to be studied. All patients had positive skin tests to inhalant allergens, a blood eosinophilia $\left(>450 / \mathrm{mm}^{3}\right)$ and a total blood IgE level above $200 \mathrm{u} / \mathrm{ml}$. SCG and bronchodilators were discontinued 24 hours before each test was carried out. Patients on oral or aerosol corticosteroids 
were excluded from the study. All were non-smokers.

Forced expiratory volume in one second $\left(\mathrm{FEV}_{1}\right)$, forced vital capacity (FVC), and maximum midexpiratory flow rates (MMEF) were measured in triplicate on a water-sealed spirometer (Godart), the best recording being used for analysis. Maximal expiratory flow volume (MEFV) curves were produced using a heated pneumotachograph (calibrated for air and helium $(\mathrm{He})$-oxygen $\left(\mathrm{O}_{2}\right)$ ) with integration of flow, and recorded on a Hewlett-Packard 7041A $\mathrm{X}-\mathrm{Y}$ recorder. Another MEFV curve was then produced after the patient had been breathing a $\mathrm{He}-\mathrm{O}_{2}$ mixture in concentrations of $79 \%$ and $21 \%$ respectively for at least one minute, which included three deep inspirations. The curves with the highest maximal flows whose vital capacities (VC) on air and $\mathrm{He}-\mathrm{O}_{2}$ matched were used for analysis. The expiratory flows at $50 \%$ VC breathing air $\left(\dot{\mathrm{V}}_{50 \mathrm{air}}\right)$ and $\mathrm{He}-\mathrm{O}_{2}$ $\left(\dot{\mathrm{V}}_{50 \mathrm{He}}\right)$ were measured, and the degree of density dependence was assessed as the ratio of $\dot{V}_{50 \mathrm{He}}$ to $\dot{V}_{50 \text { air. }}$ Responders were those patients in whom the ratio $\dot{V}_{50 \mathrm{He}}$ to $\dot{\mathrm{V}}_{50 \text { air }}$ was over $1 \cdot 20$. Where necessary, volumes were corrected to BTPS. Predicted normal values were taken from Cotes (1975) for $\mathrm{FEV}_{1}$ and FVC and from Cherniak and Raber (1972) for MMEF.

Exercise testing consisted of steady state running on an inclined treadmill $\left(10^{\circ}\right)$ for between five and eight minutes. The speed of the treadmill was adjusted so that the patient's pulse rate at the end of the exercise was at least $170-180$ beats $/ \mathrm{min}$. The same setting and duration was used for each test in any one patient. The four exercise tests performed on each patient were all completed within 10 days.

The studies were carried out in a random doubleblind fashion using the following agents administered by Wright's nebuliser during 10 minutes' tidal breathing, flow rate $8 \mathrm{l} / \mathrm{min}$ : (1) SCG nebuliser solution $(10 \mathrm{G} / \mathrm{l})$ - estimated dose nebulised $20 \mathrm{mg}$; (2) IB (1G/1)-estimated dose nebulised $2.0 \mathrm{mg}$; (3) SCG (10G/1)+IB (1G/l) solutions; and (4) saline solution $(9 \mathrm{G} / \mathrm{l})$. Following baseline measurements of FEV $_{1}$, FVC, MMEF, and MEFV curves breathing air and $\mathrm{He}-\mathrm{O}_{2}$, the drug solution was inhaled for two periods of five minutes separated by an interval of one minute. After 20 minutes spirometry was repeated, and then at $2,5,10,15$, and 20 minutes after the exercise test. In three subjects MEFV curves breathing air and $\mathrm{He}-\mathrm{O}_{2}$ were also recorded between 5 and 10 minutes post exercise. A positive response was defined as one in which there was a decrease in $\mathrm{FEV}_{1}$ of more than $20 \%$. Results of exercise tests were expressed as the maximum post-exercise fall in pulmonary function recording as a percentage of post-drug or placebo baseline. Statistical analysis was performed using Student's paired and unpaired $t$ tests.

\section{Results}

In eight of the 13 patients studied, the baseline ratio $\dot{\mathrm{V}}_{50 \mathrm{He}} / \dot{\mathrm{V}}_{50 \text { air }}$ was over $1 \cdot 20$, and these were called responders; the remaining five patients were called non-responders. Hereafter, we refer to the results in these two groups.

The results of the tests are given in tables 1 and 2 . There was no significant difference between the mean baseline values, expressed as percentage of predicted $\mathrm{FEV}_{1}, \mathrm{FVC}$, or MMEF, before aerosol administration on the four days. Mean baseline MMEF was significantly lower in non-responders $(\mathrm{P}<0.02)$, but there were no significant differences in $F E V_{1}$ or FVC.

SCG $(P<0.02)$, IB $(P<0.01)$, and IB plus SCG $(P<0.01)$ all significantly inhibited the percentage fall in $F E V_{1}$ after exercise in the responders. IB, however, had no preventive action in the nonresponders, unlike both SCG $(\mathrm{P}<0.05)$ and IB plus SCG $(P<0.02)$. IB had no significant effect on FVC in non-responders. SCG significantly prevented the fall in MMEF in both responders $(\mathrm{P}<0.02)$ and nonresponders $(P<0.05)$, while IB had no preventive action in either group.

In responders the drugs shown to have a significant inhibitory action were equally effective in preventing the percentage fall in $\mathrm{FEV}_{1}$ and MMEF. In the nonresponders SCG was superior to IB in preventing the percentage fall in $\mathrm{FEV}_{1}(\mathrm{P}<0.05)$ and $\mathrm{MMEF}$ $(P<0.02)$ but not FVC. The combination of SCG plus IB also reduced the percentage fall in $\mathrm{FEV}_{1}$ $(\mathrm{P}<0.02)$, MMEF $(\mathrm{P}<0.01)$, and FVC $(\mathrm{P}<0.05)$ compared with IB. There was no difference, however, between SCG and SCG plus IB in the non-responders.

There were no differences between the falls in ventilatory capacity after the control exercise in the two groups. Figures 1 and 2 show the individual values for FEV 1 and MMEF in both responders and non-responders.

In the three patients in whom $\dot{\mathrm{V}}_{50 \mathrm{He}} / \dot{\mathrm{V}}_{50 \text { air }}$ was measured after exercise, the ratio increased in one from 1.29 to $1 \cdot 35$, in another it fell from 1.57 to $1 \cdot 00$, while in the third it remained $1 \cdot 00$. These postexercise values all refer to post-IB exercise.

No side effects were noted during the study after any of the drugs used.

\section{Discussion}

Patients with asthma have been separated into two groups by measuring the MMEF response to low density gas breathing (Despas et al, 1972). Those showing an increase in flow rates on breathing helium are thought to have the major site of resistance to expiratory flow in the large central airways (responders), while in those showing no such increase the 

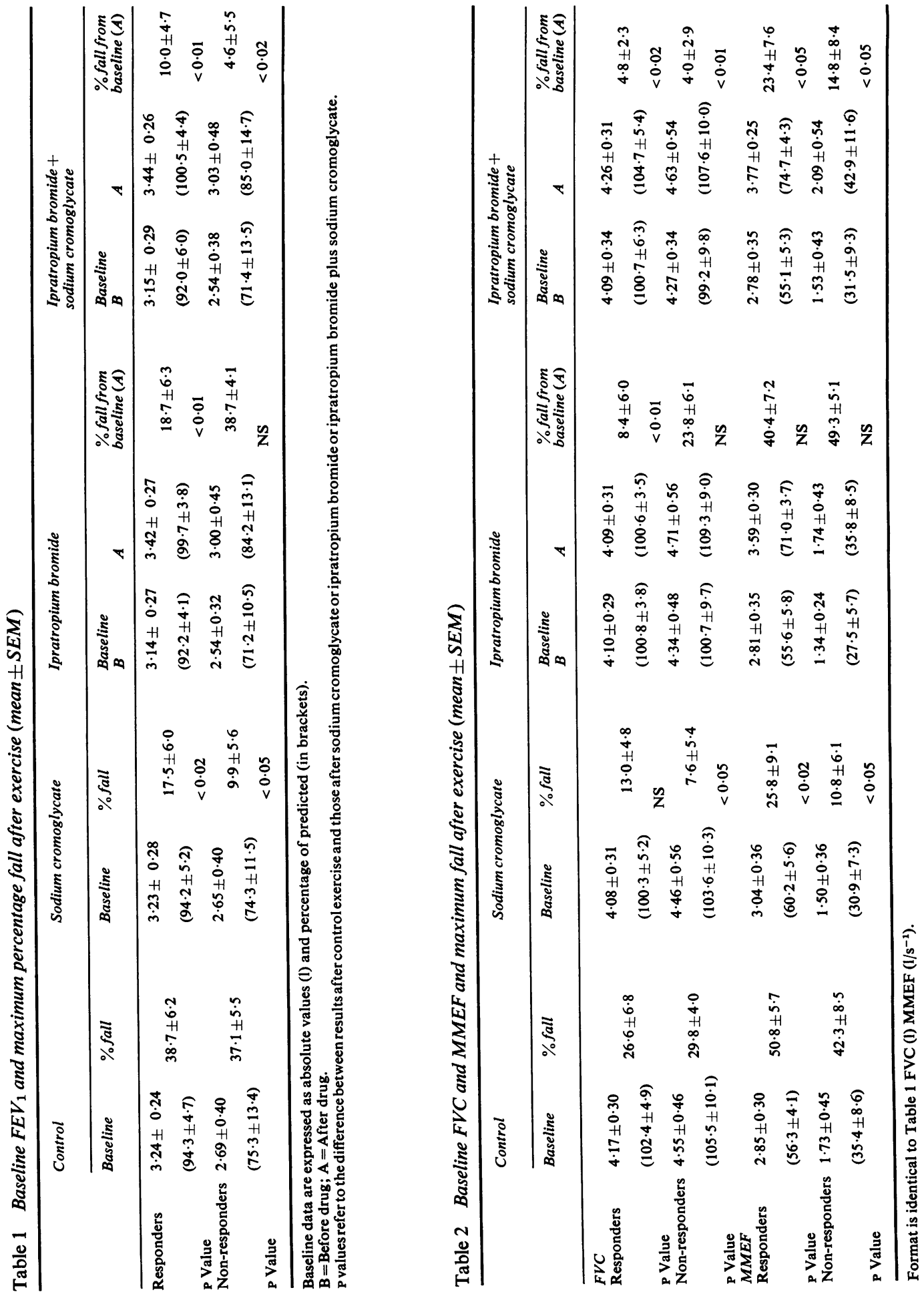

항

ळ

$\vec{\circ}$

$\overrightarrow{\vec{\omega}}$

$\ddot{\omega}$

\&

운

$\overrightarrow{0}$

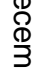

ס্ণ

ஸे

ํํㅇ

흔

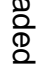

홍

亭

호

ญ्र

훙

ㅇํํ

옥

은

ज

N

స్

产

당

$\stackrel{\mathscr{9}}{?}$

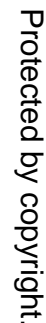




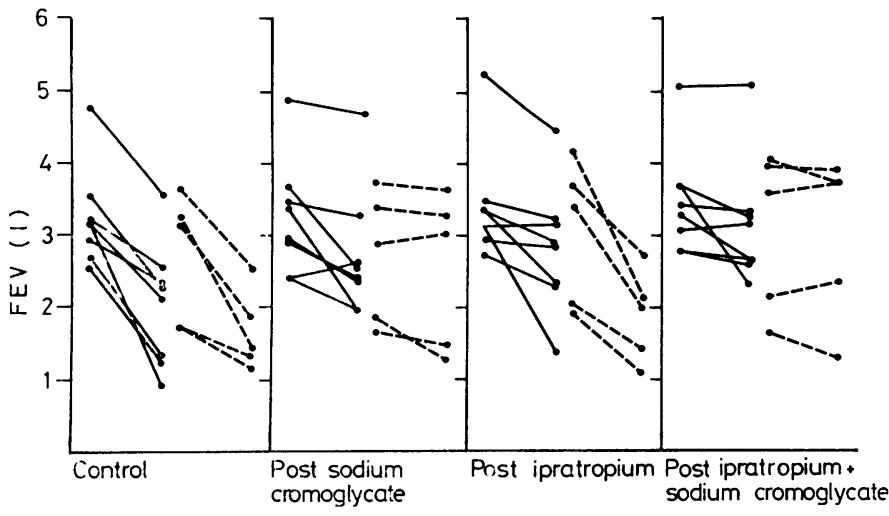

Fig 1 Effect of exercise on absolute values for $F E V_{1}$ in responders (-) and nonresponders (------) after control exercise, post sodium cromoglycate, post ipratropium bromide, and post ipratropium bromide plus sodium cromoglycate.

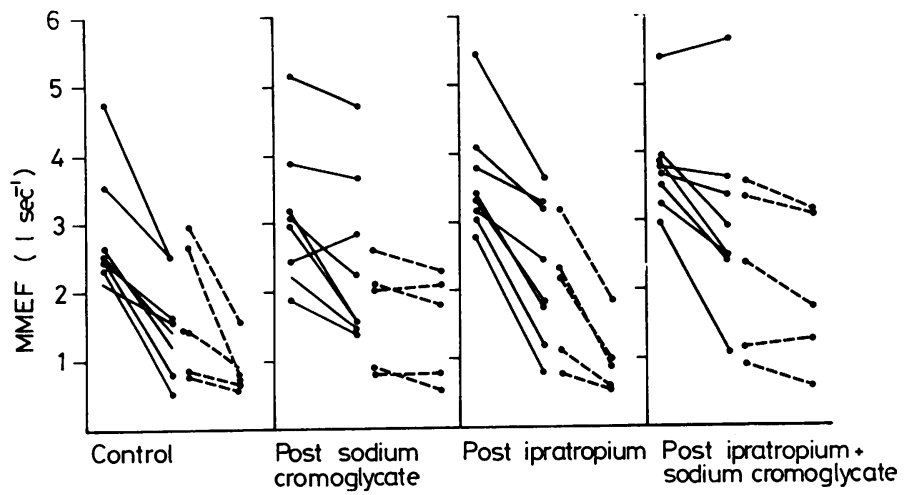

Fig 2 Effect of exercise on absolute values for $M M E F$ in responders (-) and nonresponders (-----) after control exercise, post sodium cromoglycate, post ipratropium bromide, and post ipratropium bromide plus sodium cromoglycate.

major site is thought to be in the small peripheral airways (non-responders). Other factors affecting the major site of obstruction may be cigarette smoking and the presence of chronic bronchitis or recurrent respiratory infections (Antic and Macklem, 1976). Using this classification, eight patients in our study were responders while five were non-responders. The predicted baseline values of FEV 1 and FVC did not differ between the two groups. Non-responders had, however, significantly lower flow rates in small airways as assessed by baseline MMEF rates (McFadden and Linden, 1972).

In this study both SCG alone and in combination with IB inhibited EIA, as measured by fall in FEV , in both responders and non-responders, while IB had a preventive action only in responders. IB had no inhibitory activity, however, in either responders or non-responders when assessed by the change in MMEF, while SCG was significantly inhibitory in both these groups. If MMEF is a test of small airways calibre then IB unlike SCG would appear to have no inhibitory action on these airways. In both responders and non-responders there was no difference in the effectiveness of the drugs shown to have a preventive action on EIA. SCG, although given in nebulised form which is likely to have increased its penetration into the lungs, was given in the dose normally used from a spinhaler. Our findings, therefore, confirm its effect in EIA reported by others (Davies, 1968; Godfrey and König, 1976). The estimated dose of IB nebulised was $2.0 \mathrm{mg}$, which is 50 times the normal therapeutic dose. Higher doses of anticholinergic agents are required to block reflex vagal bronchoconstriction in animals (Widdicombe and Stirling, 1970), but from our unreported sources this did not appear to be the case in our previous study in which the EIA of four of nine subjects was not prevented by $0.5 \mathrm{mg}$ of IB or $10 \mathrm{mg}$ of atropine. In previous studies comparing SCG and IB in extrinsic asthmatics Chan-Yeung (1977) reported the prevention of EIA in three out of four patients by IB and in all by SCG, while Godfrey and König (1976) prevented EIA in three out of seven patients with atropine methonitrate and six out of seven with SCG. These authors did not, however, identify any differences between their patients and the therapeutic responses observed.

McFadden et al (1977) studied 12 patients with 
EIA who were all responders before exercise. IB inhibited those in whom density dependence increased after exercise indicating predominantly large airways obstruction but had no effect in those with predominantly small airways obstruction as assessed by a decrease in density dependence. This latter group, however, showed diminution in EIA by the addition of SCG. Despite not giving SCG alone, they proposed that mediator release might serve to initiate reflex bronchoconstriction. In our study post-exercise density dependence was measured in two responders, one showing an increase and the other a decrease in density dependence. The response to IB in these two patients was similar to that predicted by McFadden et al (1977). The non-responder before exercise remained so after exercise as has been found by others (Chang Yeung et al, 1976).

Our results are in keeping with IB acting mainly in the large airways and SCG acting in both small and large airways. In addition, SCG by nebuliser appears to be equally effective in both responders and nonresponders. SCG inhibits mediator release from mast cells (Orr et al, 1970) while IB could have two sites of action, either directly on cholinergic receptors in bronchial smooth muscle or on mast cells preventing mediator release (Kaliner et al, 1972). This latter action of IB seems unlikely since SCG was effective in patients in whom IB was not. We propose, therefore, that mediator release is important in most extrinsic asthmatics with EIA. In those in whom the main site of airflow obstruction is in the large central airways, which are predominantly under vagal control, mediator release results in bronchoconstriction due to cholinergic mechanisms and direct smooth muscle action. When the main site of airflow obstruction is in the smaller airways under lesser vagal control, mediator release causes bronchoconstriction due to its direct action on smooth muscle, cholinergic activity being of little importance to overall airways calibre. In support of our findings the vagus nerve predominantly effects bronchomotor tone in the large airways (Vincent et al, 1970; Simonsson, 1972), and atropine has proportionally greater activity in these airways (Cavenaugh and Cooper, 1976; Ingram et al, 1977). It would appear, however, that this proposed mechanism may not be relevant in all patients as the post-exercise fall in two of our subjects was not inhibited by any of the drugs used. In addition, from a practical therapeutic standpoint, SCG is likely to be superior to IB in the prevention of EIA in extrinsic asthmatics in whom helium response is not known.

This study was partly supported by a grant from Fisons Ltd.

\section{References}

Antic, R, and Macklem, P T (1976). The influence of clinical factors on site of airway obstruction in asthma. American Review of Respiratory Disease, 114, 851-859.

Cavanaugh, M J, and Cooper, D M (1976). Inhaled atropine sulphate: dose response characteristics. American Review of Respiratory Disease, 114, 517524.

Chan-Yeung, M, Abboud, R, Tsao, M S, and MacLean, L (1976). Effect of helium on maximal expiratory flow in patients with asthma before and during induced bronchoconstriction. American Review of Respiratory Disease, 113, 433-443.

Chan-Yeung, M (1977). The effect of SCh 1000 and disodium cromoglycate on exercise-induced asthma. Chest, 71, 320-323.

Cherniack, R M, and Raber, M B (1972). Normal standards for ventilatory function using an automated wedge spirometer. American Review of Respiratory Disease, 106, 38-46.

Cotes, J E (1975). Lung Function, 3rd edn, p 380. Blackwell, Oxford.

Davies, S E (1968). Effect of disodium cromoglycate on exercise-induced asthma. British Medical Journal, 3, 593-594.

Despas, P J, Leroux, M, and Macklem, P T (1972). Site of airway obstruction in asthma as determined by measuring maximal expiratory flow breathing air and a helium-oxygen mixture. Journal of Clinical Investigation, 51, 3235-3243.

Godfrey, S, and Konig, P (1976). Inhibition of exerciseinduced asthma by different pharmacological pathways. Thorax, 31, 137-143.

Gold, W M (1975). The role of the parasympathetic nervous system in airways disease. Postgraduate Medical Journal, 51, suppl 7, 53-62.

Ingram, $\mathbf{R} \mathbf{H}$, Wellman, $\mathbf{J} \mathbf{J}$, McFadden, $\mathrm{E} \mathbf{R}$, and Mead, J (1977). Relative contributions of large and small airways to flow limitation in normal subjects before and after atropine and isoproterenol. Journal of Clinical Investigations, 59, 696-703.

Kaliner, M, Orange, R P, and Austen, K F (1972). Immunological release of histamine and slow reacting substance of anaphylaxis from human lung. IV. Enhancement by cholinergic and alpha-adrenergic stimulation. Journal of Experimental Medicine, 136, 556-567.

Lancet (1976). Arms and the bronchi. 1, 287-289.

McFadden, E R, and Linden, D A (1972). A reduction in maximum mid-expiratory flow rate; a spirographic manifestation of small airway disease. American Journal of Medicine, 52, 725-737.

McFadden, E R, Ingram, $\mathbf{R} \mathbf{H}$, Haynes, $\mathbf{R} \mathrm{L}$, and Wellman, J J (1977). Predominant site of flow limitation and mechanisms of post-exertional asthma. Journal of A pplied Physiology, 42, 746-752.

Orr, T S C, Pollard, M C, Gwilliam, J, and Cox, J S G (1970). Mode of action of disodium cromoglycate studies on immediate type hypersensitivity reactions using “double sensitization' with two anti- 
genically distinct rat reagins. Clinical and Experimental Immunology, 7, 745-757.

Simonsson, B G (1972). Reflex control of airways calibre. Bulletin de Physio-Pathologie Respiratoire, 8, 439-446.

Tinkelman, D G, Cavenaugh, $\mathbf{M}$ J, and Cooper, D M (1976). Inhibition of exercise-induced bronchospasm by atropine. American Review of Respiratory Disease, 114, 87-94.

Vincent, N J, Knudson, R, Leith, D E, Macklem, P T, and Mead, J (1970). Factors influencing pulmonary resistance. Journal of Applied Physiology, 29, 236243.

Widdicombe, J G, and Stirling, G M (1970). The autonomic nervous system and breathing. Archives of Internal Medicine, 126, 311-328.

Requests for reprints to: Dr Neil C Thomson, Department of Respiratory Medicine, Western Infirmary, Glasgow G11 6NT. 